\title{
Cross-sectional echocardiographic assessment of coarctation in the sick neonate and infant
}

\author{
J F SMALLHORN, J C HUHTA „^ P A ADAMS,† R H ANDERSON, J L WILKINSON,‡ \\ F J MACARTNEY
}

From the Thoracic Unit, The Hospital for Sick Children, London

SUMMARY To establish an integrated non-invasive method for diagnosing coarctation, crosssectional echocardiographic appearances of 48 neonates and infants with coarctation were combined with clinical information on the peripheral pulses. Measurements of the ascending aorta, aortic arch, and isthmus were made and compared with those from controls matched for weight and age. Confirmation of the coarctation was available in all cases. Angiocardiographic measurements were performed in 15 patients from either the group with coarctation or the controls. After the aortic arch had been analysed segment by segment $\mathbf{4 0}$ patients were found to have preductal coarctation, five juxtaductal coarctation, and three postductal coarctation. In one of the patients in the latter group the obstruction was situated in the abdominal aorta. Specific echocardiographic features were present in each subgroup. Echocardiographic measurements were about two thirds of those obtained by angiocardiography. By combining information on the peripheral pulses, isthmic size, and the presence of a discrete shelf in the aorta it was retrospectively possible to predict correctly the presence of coarctation in 45 out of 48 cases. Since the beginning of this study 29 patients have undergone surgery without prior invasive investigation. A combination of clinical assessment and cross-sectional echocardiographic features allows a reliable diagnosis of coarctation to be made in most cases.

Coarctation of the aorta is one of the commonest causes of congestive heart failure in neonates and infants. While the diagnosis is relatively straightforward when the femoral pulses are absent, the presence of a major persistent ductus arteriosus may make distal pulses palpable. Associated intracardiac defects are common and play an important role in patient management. ${ }^{1}$ Clinical detection of these associated abnormalities has been difficult with traditional noninvasive techniques. The cross-sectional echocardiographic appearances of the commoner associated defects (such as ventricular septal defect with mitral

Present address: ^Department of Paediatric Cardiology, Texas Children's Hospital, 6620 Fannin, Houston, Texas 77030, USA.

†Department of Paediatric Cardiology, Adelaide Children's Hospital Inc, North Adelaide, South Australia 5006.

¥Royal Liverpool Children's Hospital, Myrtle Street, Liverpool, L7 7DG.

JCH was a British Heart Foundation overseas research fellow, RHA and FJM are supported by the British Heart Foundation and the Joseph Levy and Vandervell Foundations respectively.

Accepted for publication 14 June 1983 stenosis or ductus arteriosus) have been well documented, ${ }^{2-4}$ but little attention has been paid to recognition of the coarctation itself. ${ }^{5}$ Furthermore, correlative echocardiographic, angiocardiographic, and morphological detail is lacking.

Our preliminary observations had suggested that neither cross-sectional echocardiography nor clinical examination on its own was sufficiently accurate to diagnose coarctation. Clinical diagnosis was made particularly difficult because several patients in whom the diagnosis had been suspected at the referring hospital had been treated with prostaglandins during transport to this unit. By the time we examined them there was no peripheral pulse inequality.

The objective of this study was therefore to establish how best to diagnose coarctation with crosssectional echocardiography and to see if accuracy could further be improved by combining this information with that from clinical examination of the patient.

Following the suggestion of Marquis and Godman, 6 we have used the term ductus only if that structure is patent, whether it is persistent or not. 


\section{Patients and methods}

During an 18 month period, 48 neonates and infants with coarctation of the aorta were seen at this hospital. The patients were studied before undergoing any invasive procedure, which is the policy for all children at this institution. Attention was paid to the presence and nature of the femoral pulses, which were then compared with those of the upper limb pulses and the results documented.

Initial cross-sectional echocardiograms were made of the heart itself to determine the sequential segmental arrangement and presence of intracardiac associated malformations as described elsewhere. ${ }^{78}$ To examine the great arteries the scan head was placed in the suprasternal position such that the beam was parallel to the frontal plane of the body. Here the pulmonary artery size was assessed. The scan head was then rotated anticlockwise in patients with a left aortic arch until the aorta was seen in its long axis. The number and size of the brachiocephalic arteries were noted. Further counter clockwise and leftward angulation of the transducer allowed visualisation of the region where a ductus or ligamentum would enter the descending aorta. In most cases the transducer was moved to a position just below the left clavicle to obtain this view. In both these views the size of aortic arch, isthmus, and ascending aorta were assessed. Similarly the presence of the ductus or ligamentum was noted.

Mitral annular size was assessed as previously described. ${ }^{3}$ Similarly, the ascending aorta, arch, isthmus, and descending aorta were measured by photographing the relevant segment at its maximum diameter. The ascending aorta was measured just proximal to the origin of the brachiocephalic artery, the arch just distal to the left carotid artery, and the isthmus just distal to the left subclavian artery (Fig. 1). The descending aorta was measured below the diaphragm proximal to the origin of the superior mesenteric artery and at least $5 \mathrm{~cm}$ below the site of the coarctation (Fig. 2). All measurements of the aorta were made from the internal diameters, as it was not possible reliably to visualise external boundaries of each segment. The equivalent measurements of the ascending aorta, arch, isthmus, and descending aorta were made in a control group of 25 neonates and infants with neither coarctation of the aorta nor reduced pulmonary blood flow. In this group of patients five had a small ventricular septal defect, two a moderate sized ventricular septal defect, three an atrial septal defect in the fossa ovalis, and the remainder a normal heart.

In the total population, 15 patients had angiocardiographic demonstration of the size of the aorta and the presence or absence of a coarctation. In this group

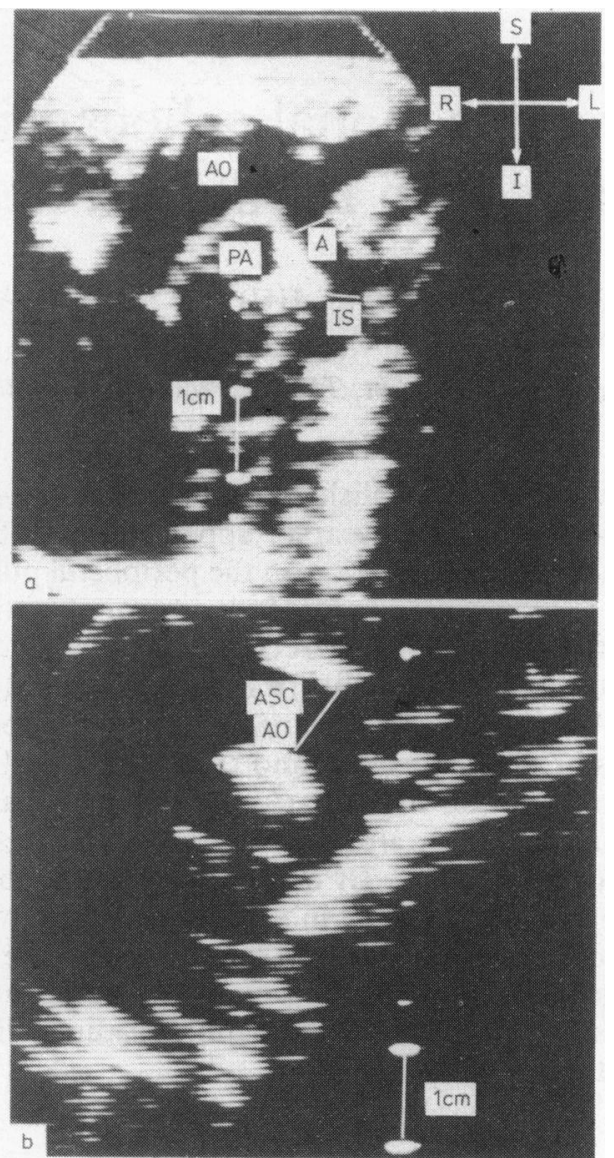

Fig. 1 Cross-sectional echocardiograms of a suprasternal long axis cut of the aorta showing $(a)$ the site of the measurements of the arch and isthmus, and (b) (a different case) the site selected for measurement of the ascending aorta. Note that the internal diameters are selected and that the arch and isthmus run in the lateral plane. A, arch; AO, aorta; ASC Ao, ascending aorta; IS, isthmus; $P A$, pulmonary artery.

similar angiocardiographic measurements were correlated with those obtained by echocardiography. To compensate for age, weight, and $x$ ray magnification (owing to the lack of a grid on the angiocardiogram) a ratio of the normal diameter of the arch to the ascending aorta, arch to descending aorta, isthmus to ascending aorta, and isthmus to descending aorta was calculated. ${ }^{9}$ In the group of patients with coarctation, all had surgical or necropsy confirmation of the site of obstruction, or both.

Statistical analysis was carried out using the SPSS package on the University of London computer. The methods used were standard descriptive statistics, unpaired $t$ tests, bivariate regression analysis, analysis 


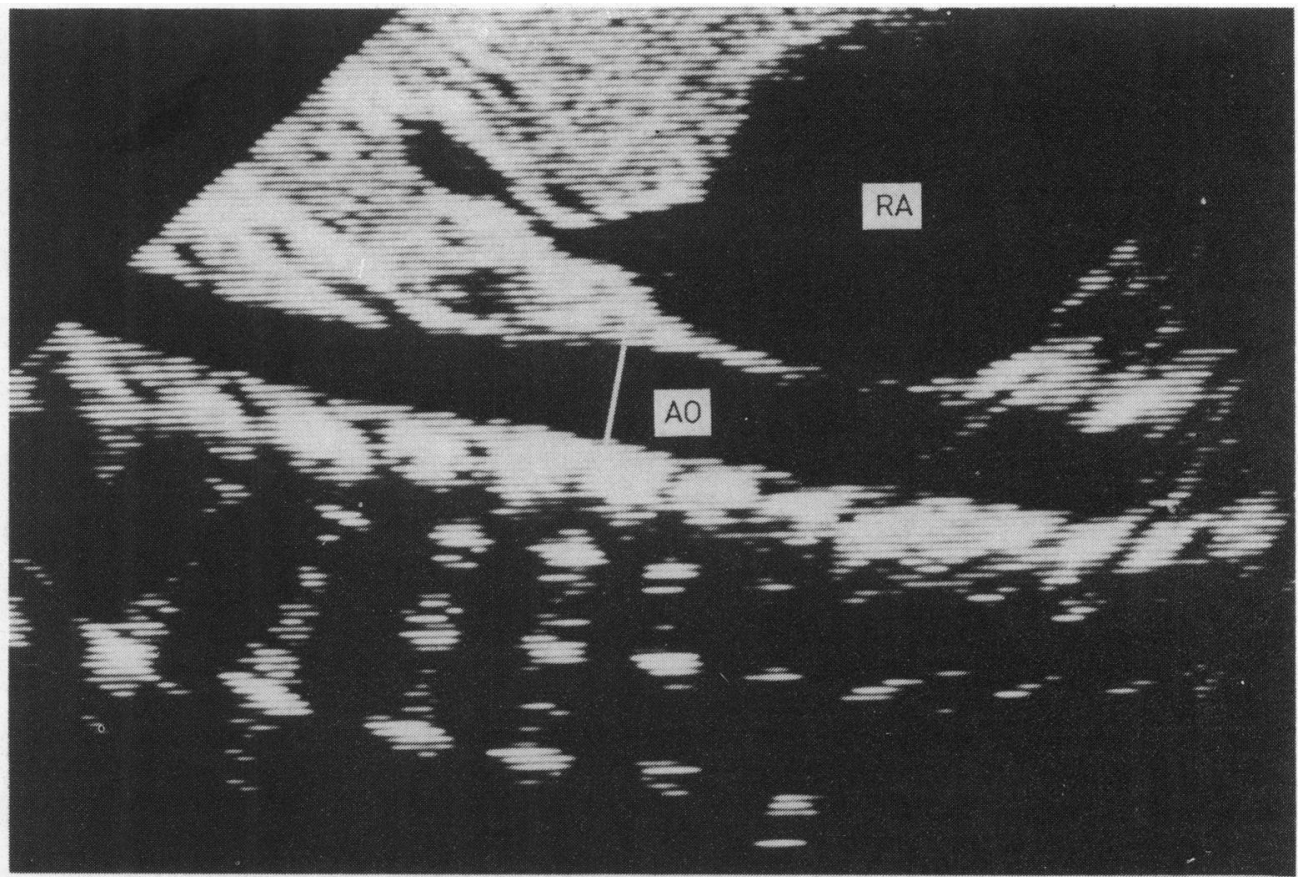

Fig. 2 Cross-sectional echocardiogram of a subcostal cut showing a normal descending aorta and the site of measurement selected. Note that the vessel is in the axial plane. RA, right atrium.

of covariance, and discriminant function analysis. Tests of significance were two tailed with a critical probability of 0.05 for rejection of the null hypothesis.

\section{Results}

\section{STUDY POPULATIONS}

The ages of the 48 patients with coarctation varied from 2 to 190 days at the time of echocardiography (median 16.5 days), while those of the 25 controls varied from 1 to 175 days (median 40.3 days). There was no significant difference between patients and controls with regard to age or body weight.

Of those patients with coarctation, six had normal peripheral pulses, four symmetrical but weak pulses, eight good volume upper limb pulses and poor femoral pulses, and the remainder absent femoral pulses. It must be stressed that in many cases the patients were receiving prostaglandin $\mathrm{E}_{1}$ at the time they were examined, the infusion having been started at the referring hospital.

\section{VISUALISATION OF COARCTATION}

In the neonate and infant it was not possible in all cases to see the whole aortic arch in one long axis cut. Sometimes the aorta has a slight kink in the isthmic region where a previous ductus inserted. As the lateral resolution of the transducer deteriorates with increasing depth, so is visualisation of the third part of the aortic arch hampered. For these reasons, it was necessary to study the anatomy of the aortic arch and descending aorta using several different views rather than attempt to obtain all the information in one cut.

The standard high right parasternal or suprasternal views were adequate for visualisation of the ascending aorta, the transverse arch, and the upper part of the isthmus as well as the arch arteries, in particular the left subclavian artery (Fig. 3). When the transducer was moved to just below the left clavicle, however, the beam then transected the descending aorta, the pulmonary trunk, and the left pulmonary artery in their long axis. It was in this region that the area opposite and below the ductus or ligamentum could be seen ${ }^{4}$ (Fig. 3). Even when this region was slightly tortuous the lumen could be readily visualised in its entirety. The abdominal aorta was best scanned from the subcostal approach with the transducer beam perpendicular to the frontal plane of the body (Fig. 2). Here it could be followed from just above the diaphragm to its bifurcation into the common iliac arteries.

Applying this segment by segment approach, 40 patients had coarctation proximal to the entry site of 


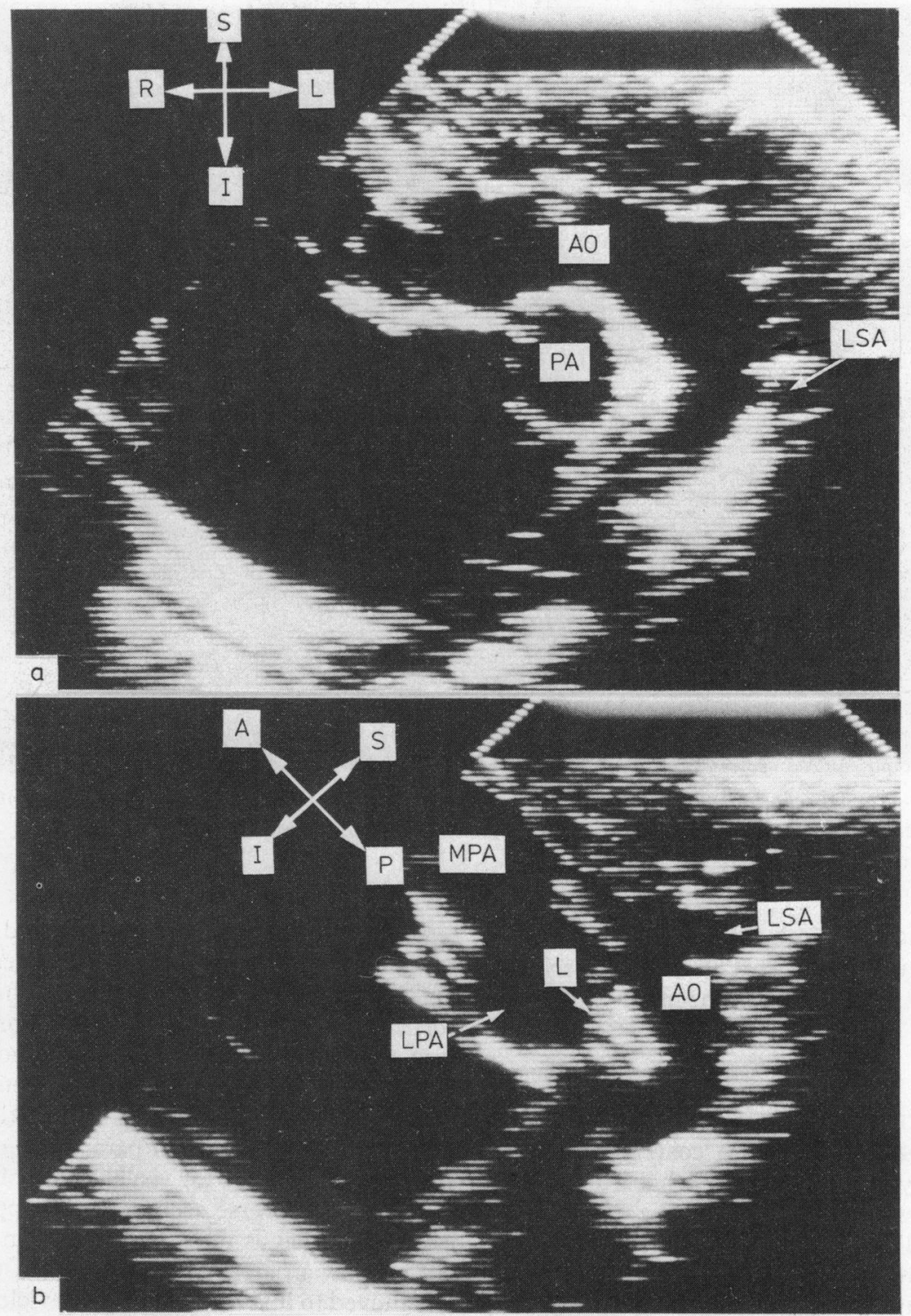

Fig. 3 Cross-sectional echocardiogram of (a) a suprastermal long axis cut in a neonate without coarctation (note that the region distal to the left subclavian artery is unclear) and (b) (in the same patient) of a ductal cut showing a ligamentum with the third part of the aortic arch now being clearly visualised. $L$, ligamentum; LPA, left pulmonary artery; $L S A$, lefi subclavian artery; MPA, main pulmonary artery; $A$, arch; $A O$, aorta; $P A$, pulmonary artery.

the ductus or ligamentum (preductal, Fig. 4). Five had coarctation opposite the entry site of the ductus or ligamentum (juxtaductal, Fig. 5) and in three it was distal (postductal, Fig. 6). In one of the latter group the obstruction was situated in the abdominal aorta (Fig. 7). A shelf was observed in all cases with juxta- ductal coarctation, in the two with a discrete postductal coarctation, and in 31 out of $40(78 \%)$ with preductal coarctation. One false positive diagnosis of coarctation was made early in the course of the study because of misinterpretation of an anterior shelf (the entry point of the ductus ${ }^{4}$ ) as a coarctation. 


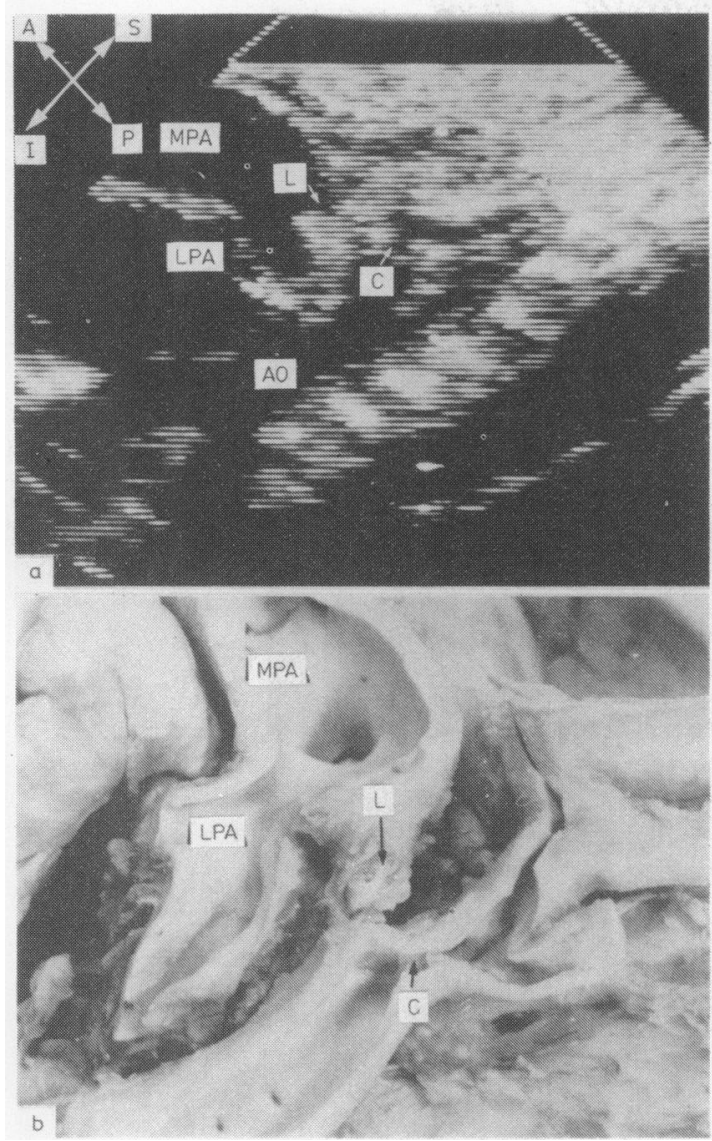

Fig. 4 (a) Cross-sectional echocardiogram of a ductal cut in a patient with preductal coarctation (note how the ligamentum is seen and its relation to the coarctation) and (b) a photograph of the morphological features in a different patient. $C$, coarctation; $L$, ligamentum; $M P A$, main pulmonary artery; $L P A$, left pulmonary artery; $A O$, aortic arch.

\section{ECHOCARDIOGRAPHIC AND}

\section{ANGIOCARDIOGRAPHIC MEASUREMENTS}

There was a reasonable correlation of the echocardiographic and angiocardiographic ratios between the diameters of the arch or isthmus and the ascending or descending aorta, with the values obtained from the echocardiogram being approximately two thirds of those on the angiocardiogram (Table). Henceforward the results obtained refer to echocardiographic data. In patients with coarctation the size of the ascending aorta increased with older age $(p<0.00001)$ and $\log 10$ weight $(p<0.001)$, but there was no significant association between age or weight and the diameter of the transverse aorta, isthmus, or descending aorta, except for a weak correlation between the diameter of the descending aorta and $\log 10$ weight $(p<0.02)$ and age $(p<0.01)$. There was no significant association between any measure of body size and the diameter of the descending aorta.

In patients with preductal coarctations, the only ones in whom a shelf was not always visible, the absolute measurement of the isthmus was $3 \mathrm{~mm}$ in diameter or less in 34 out of $37(93.3 \%)$ and $4 \mathrm{~mm}$ in diameter in three. In those with juxtaductal coarctation, the isthmus was $2 \mathrm{~mm}$ in diameter in one, $4 \mathrm{~mm}$ in diameter in two, and $4.5 \mathrm{~mm}$ in the fourth. By contrast all three patients with a postductal coarctation had an isthmus at least $5 \mathrm{~mm}$ in diameter.

In the controls, one (4\%) patient had an isthmus of $2 \mathrm{~mm}$ in diameter, four (16\%) of $3 \mathrm{~mm}$ in diameter, and nine (36\%) of $4 \mathrm{~mm}$ in diameter. In the remainder (44\%), it was $5 \mathrm{~mm}$ in diameter or greater. Discriminant function analysis was carried out in an attempt to separate controls from patients with preductal coarctation, with prior probabilities set proportional to group size. Using an isthmal diameter of $3.3 \mathrm{~mm}$ as the dividing point 34 out of $38(89.5 \%)$ preductal coarctations and 20 out of $25(80 \%)$ controls were correctly predicted. This discrimination was not improved by taking weight or age into account.

There was a significant positive correlation between $\log 10$ weight and mitral annular dimension in both controls $(p<0.001)$ and patients with coarctation $(p<0.01)$, but controlling for $\log 10$ weight there was no significant difference in annular dimension between the two groups.

A flow chart can be constructed for the noninvasive assessment of a possible coarctation of the aorta (Fig. 8) incorporating the nature of the upper and lower limb pulses, visualisation of a shelf in the ductal region, and the size of the isthmus. If the patients from this study are restrospectively assessed according to the flow chart, then 45 out of 48 (94\%) are correctly identified as having coarctation of the aorta. In the other three cases, each of whom had good volume femoral pulses, the lack of visualisation of a shelf in the ductal regions and an aortic isthmus within the range of normal prevented the correct diagnosis from being made. All had intracardiac defects which on their own could have caused cyanosis or cardiac failure, or both, and were already receiving prostaglandins at the time of admission.

\section{ASSOCIATED ANOMALIES}

All associated anomalies were correctly predicted by cross-sectional echocardiography. Situs solitus was found in 46 cases. One case of right and one of left isomerism were demonstrated. Forty five had atrioventricular concordance, one atrioventricular discordance, and two a univentricular atrioventricular connection. The ventriculo-arterial connections were concordant in 41 , discordant in four, and double out- 

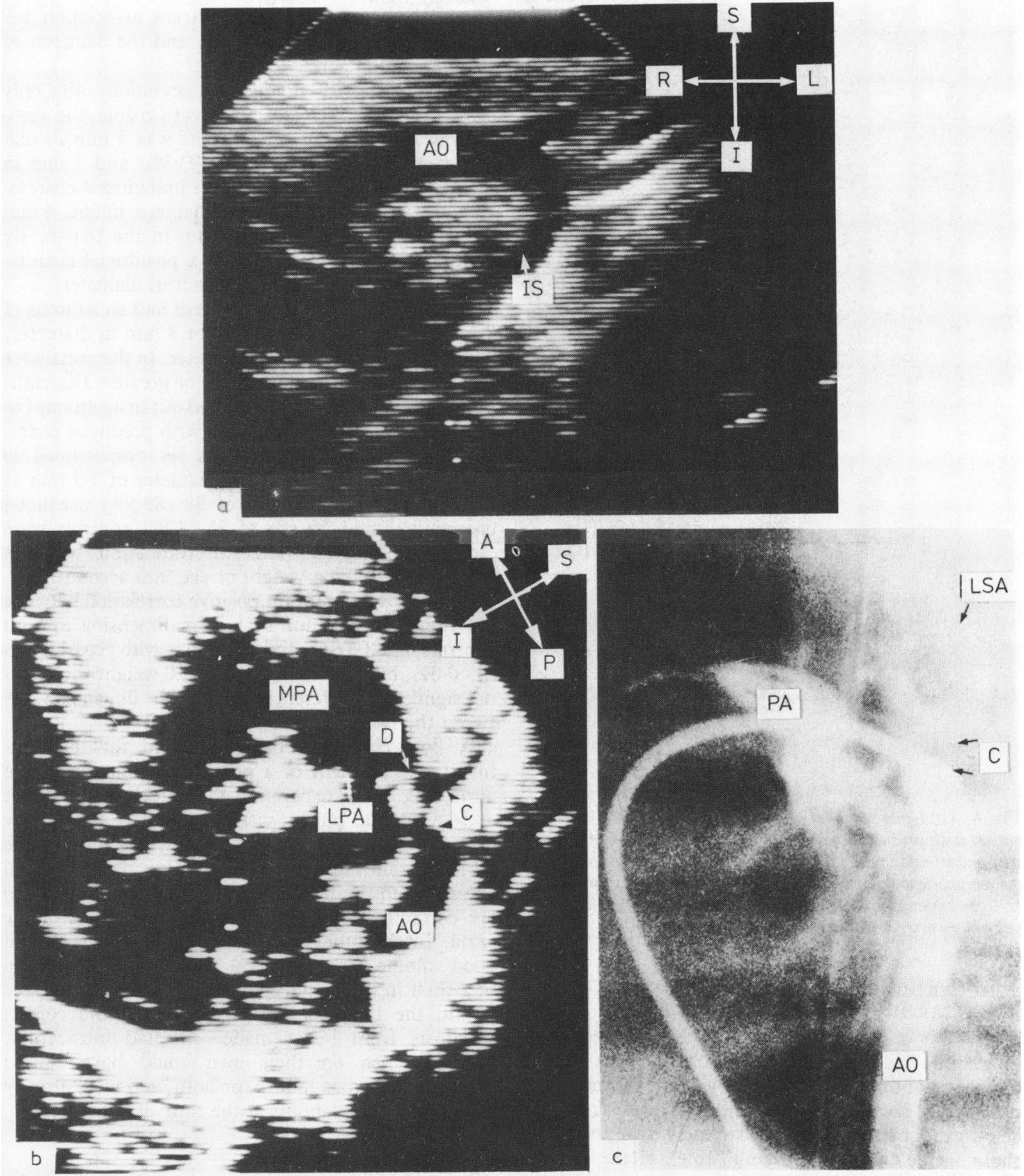

Fig. 5 (a) Cross-sectional echocardiogram of a suprasternal long axis cut in a patient with juxtaductal coarctation, in which the site of obstruction is not seen (note the normal isthmic size); (b) a cross-sectional echocardiogram (in the same patient) showing the coarctation opposite the small ductus (note the wedge shape protuding into the lumen of the aorta); and (c) an angiocardiogram (in the same patient) showing the echocardiographic features. $D$, ductus; $A O$, aorta, IS, isthmus; MPA, main pulmonary artery; LPA, left pulmonary artery; $C$, coarctation. 

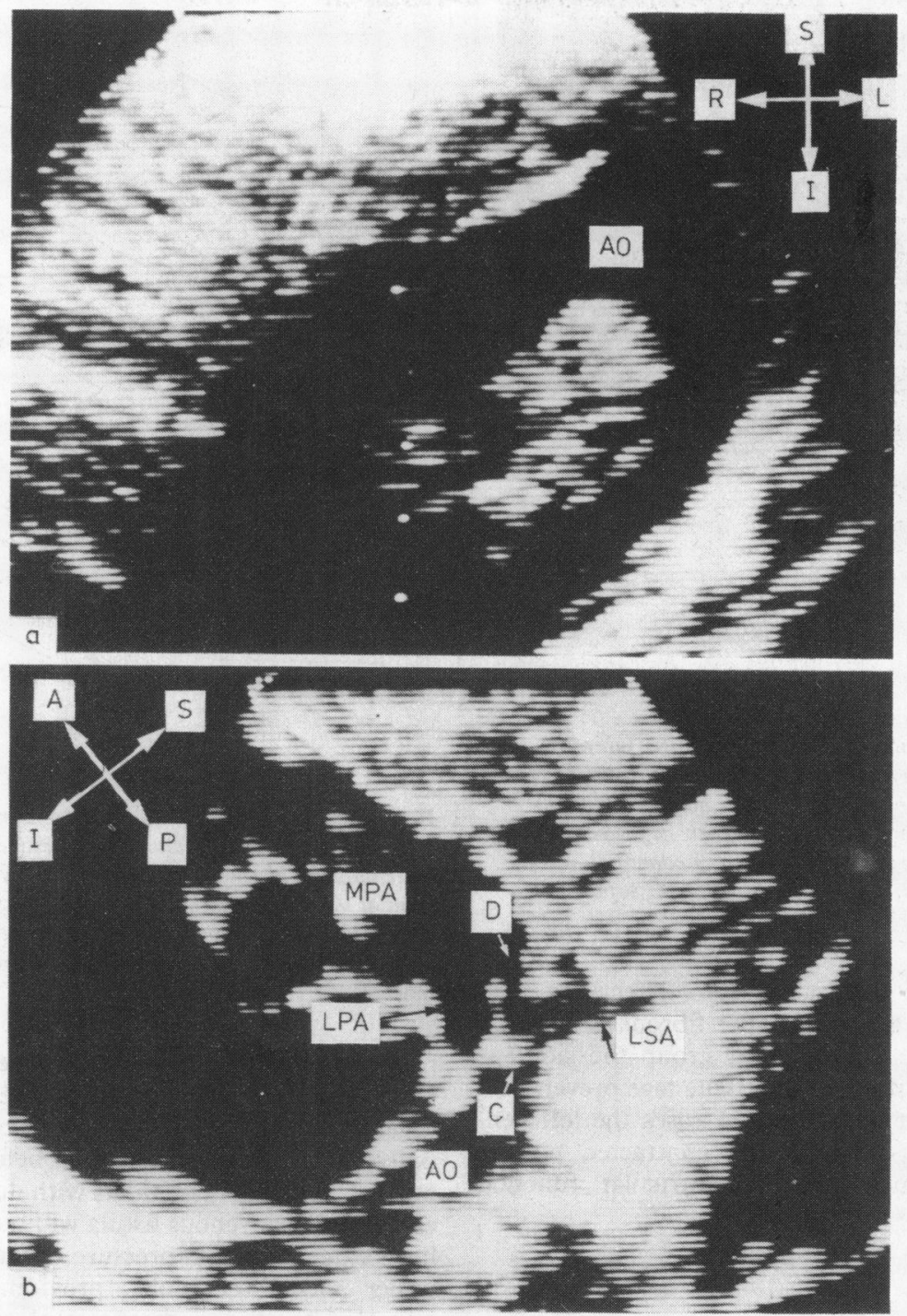

Fig. 6 Cross-sectional echocardiograms of (a) a suprasternal long axis cut in a patient with postductal coarctation (note the normal appearance of the aortic arch) and (b) of a ductal cut showing the coarctation distal to the ductus. AO, aortic arch; $D$, ductus; $C$, coarctation; LPA left pulmonary artery; MPA, main pulmonary artery.

let right ventricle in three. Two cases had an associated atrioventricular septal defect and two a left superior caval vein to coronary sinus. Nine had a bicuspid aortic valve, four of these with single papillary muscle in the left ventricle ("parachute" deformity). Two others had stenotic mitral valves with two papillary muscles.

Of those patients with atrioventricular concor- dance, 22 had an intact ventricular septum, 15 a large ventricular septal defect, five a small ventricular septal defect, and three fibrous tissue tags on the right ventricular aspect of the defect (so-called "aneurysm" of the membranous septum). Three patients with muscular trabecular defects had posterior displacement of the infundibular septum into the left ventricular outflow tract. Reliable documentation of the 


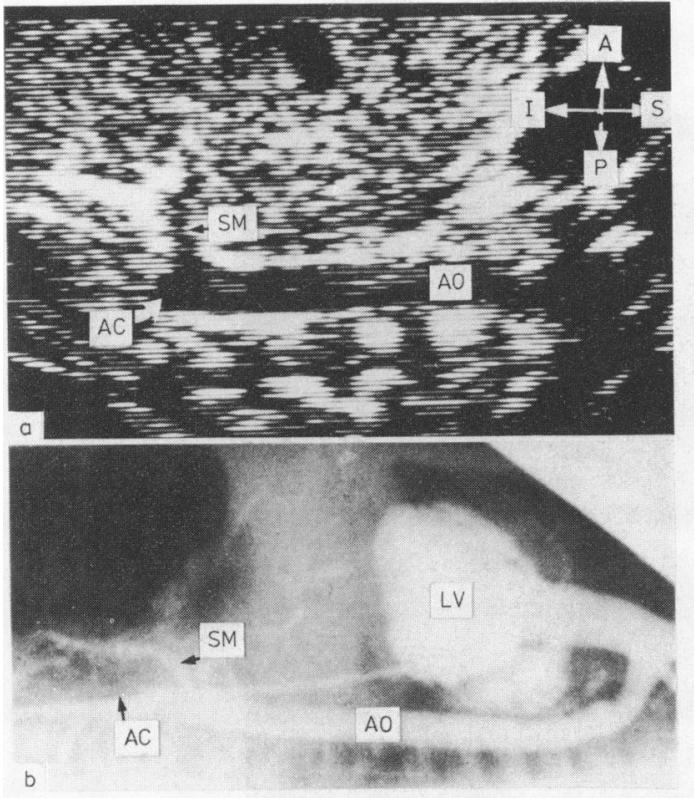

Fig. 7 (a) Cross-sectional echocardiogram of a subcostal cut of the descending aorta in a patient with abdominal coarctation (note the disappearance of the descending aorta distal to the superior mesenteric artery; compare this with Fig. 2) and (b) an angiocardiogram in the same patient. $A C$, abdominal coarctation; $A O$, aotta; $L V$, left ventricle; $S M$, superior mesenteric artery.

site and size of the ventricular septal defect was possible in all except those with the fibrous tissue tags around the defect. In the latter group the site was accurately determined but the tissue tags prevented a reliable assessment of size. In 11 cases the left ventricular cavity was dilated and contracted poorly, while in the remainder left ventricular function appeared normal.

\section{Discussion}

Coarctation of the aorta ranks sixth in frequeney of all congenital heart defects. ${ }^{10}$ The diagnosis is straightforward when the femoral pulses are absent. When the coarctation is preductal and the pulmonary artery

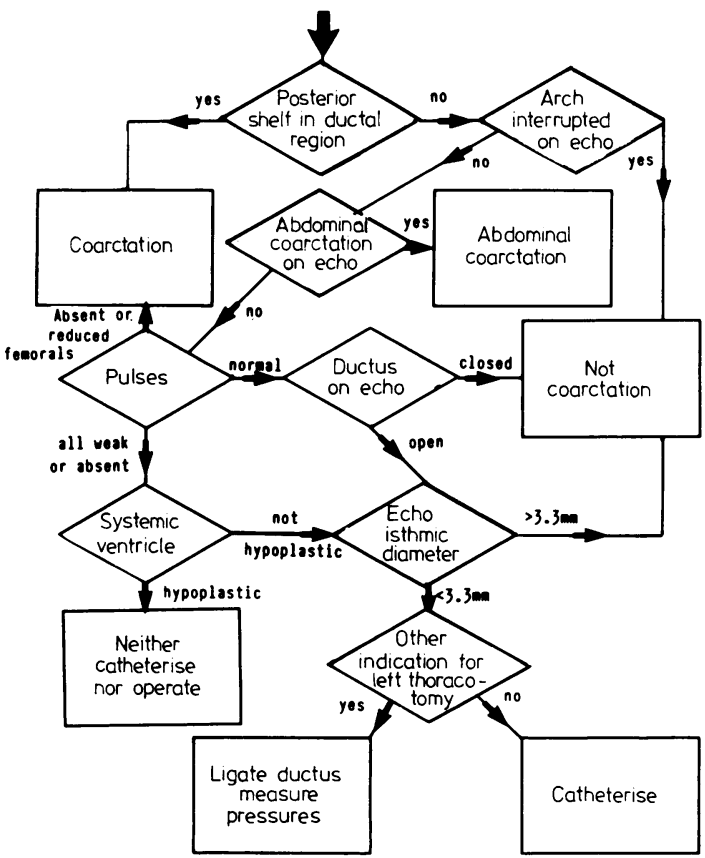

Fig. 8 Flow chart suggesting incorporation of peripheral pulses and echocardiographic features for assessment of suspected coarctation in the neonate and infant. Entry to the chart is at the point of the thick black arrow. The structure of the flow chart is such as to make it as simple as possible rather than to represent the temporal order of observations. $\diamond$ indicate choices; $\square$ indicate conclusions.

pressure is at systemic level, however, these pulses may be continuously or intermittently palpable. In other patients who present in low cardiac output the pulses may be uniformly weak before medical treatment. Occasionally, patients with ductus arteriosus or cerebral arteriovenous fistula without coarctation may have a demonstrable pressure difference between the upper and lower limbs, providing further confusion. ${ }^{11}$ The clinical diagnosis of an associated ventricular septal defect is occasionally easy, but more commonly it is exceedingly difficult. This is because the typical murmur of an isolated ventricular septal defect is absent, and it may be difficult to distinguish

Table Correlations between angiocardiographic (abscissa) and echocardiographic (ordinate) measurement of ratios between different segments of the aorta in 15 patients with coarctation of the aorta

\begin{tabular}{lllll}
\hline Ratio & Slope & Intercept & $r$ & SEE \\
\hline Arch:ascending aorta & 0.539 & 0.303 & 0.59 & 0.077 \\
Isthmus:ascending aorta & 0.677 & 0.145 & 0.75 & 0.094 \\
Arch:descending aorta & 0.78 & 0.161 & 0.74 & 0.136 \\
Isthmus:descending aorta & 0.732 & 0.132 & 0.733 & 0.133 \\
\hline
\end{tabular}

$r$, correlation coefficient; SEE standard error of the estimate. 

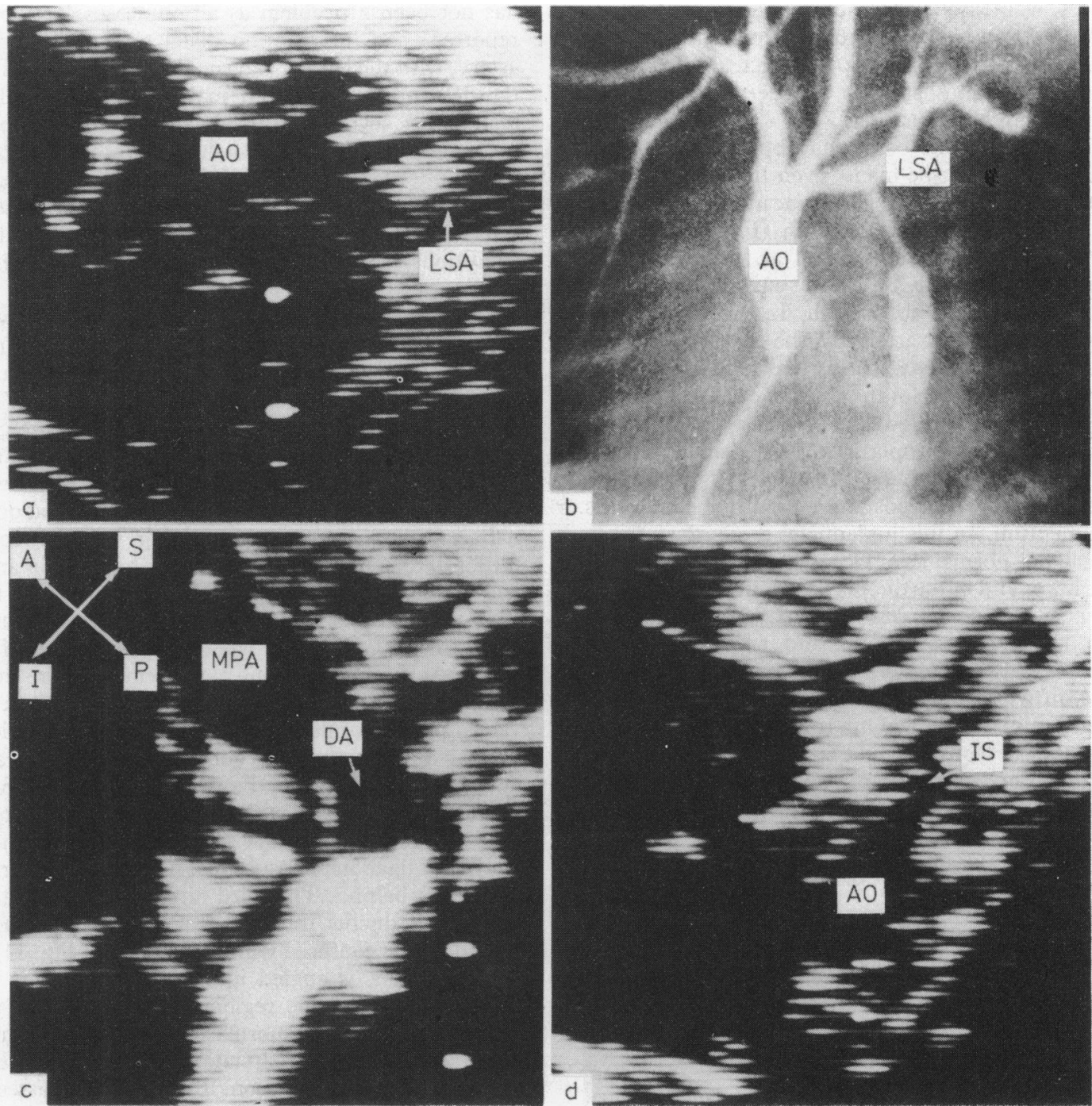

Fig. 9 (a) Cross-sectional echocardiogram of a suprasternal long axis cut in a patient with severe tubular hypoplasia of the aortic isthmus (note that the isthmus is not seen in this cut); (b) an angiocardiogram from the same patient; (c) and (d) echocardiograms (from the same patient) showing respectively the large ductus supplying the descending aorta and the narrow isthmus, the lumen of which can be seen. DA, ductus arteriosus; $A O$, aorta; MPA, main pulmonary artery; IS, isthmus.

pulmonary arterial from pulmonary venous congestion on the chest $x$ ray film.

Differentation of coarctation from interrupted aortic arch may be impossible on purely clinical grounds especially when the interruption is distal to the left subclavian artery. ${ }^{12}$ With cross-sectional echocardiography it is possible to identify reliably almost all the associated intracardiac defects, in particular the position and relative size of any ventricular septal defect. ${ }^{2}$ Mitral valve anomalies can be identified at an early stage when clinical signs are absent or non-specific. ${ }^{3}$ The detection of left ventricular outflow tract obstruction, in particular that due to posterior infundibular displacement, is also readily achieved. This may have important implications for surgical management. ${ }^{12}$

With the intracardiac anatomy delineated, attention must then be focused on the aortic arch. Before the echocardiographic features can be appreciated it is first necessary to understand the different types of coarctation and their relation to the ductus arteriosus 
or its ligamentous remnant. In the normal fetus the main pattern of flow is from the pulmonary trunk to the descending aorta via the duct. As a result the neonatal isthmus appears to insert into the ductusdescending aorta pathway. ${ }^{13}$

The distinction between tubular hypoplasia and coarctation must be made, even though the two may coexist. Tubular hypoplasia means uniform tubular narrowing of part of the arch (Fig. 9), whereas a coarctation is a descrete shelf at some point in the arch. This normally lies in the environs of the ductal junction with the aortic arch. In the young patients who have a ductus arteriosus the coarctation is due to a curtain of discrete ductus-like tissue which sometimes totally encircles the isthmic orifice. This sling is situated in the preductal position and is usually associated with hypoplasia of the isthmus and possibly more proximal regions of the arch. ${ }^{14} 15$ Alternatively, the shelf may lie opposite the mouth of the ductus or ligamentum. In this juxtaductal group the isthmus is usually of normal size. Occasionally a shelf may lie at the lower end of the ductus or ligamentum in postductal position. Very rarely there may be a shelf between the left common carotid and subclavian arteries. Abdominal coarctation is exceedingly rare and is due to a diffuse hypoplasia of the abdominal aorta rather than a discrete shelf. Our results show that all these anatomical features are easily recognised by crosssectional echocardiography (Figs. 4-7) provided the assessment is carried out by examining each segment of the arch in turn.

So far, differentiation from interrupted aortic arch

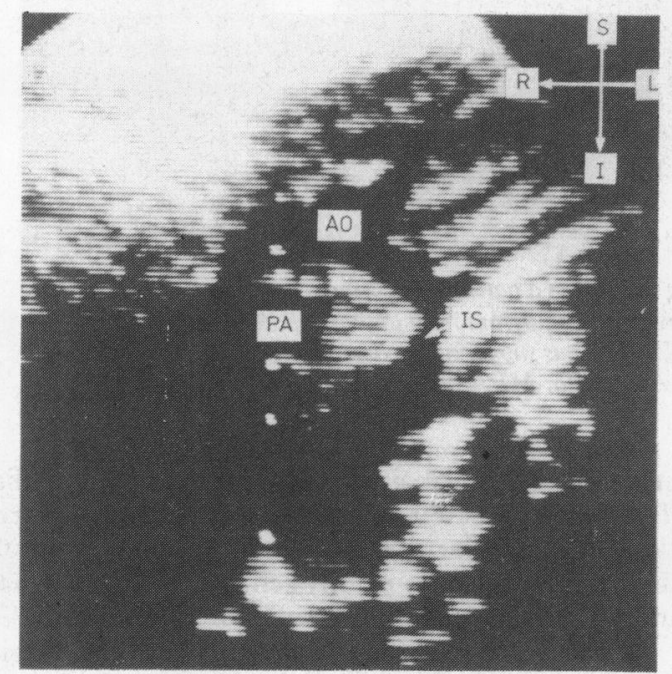

Fig. 10 Cross-sectional echocardiogram of a suprasternal long axis cut showing only isthmic hypoplasia. Subsequent cardiac catheterisation also showed an associated discrete coarctation. $A O$, aorta; $P A$, pulmonary artery; IS, isthmus. has not been a problem as all our cases (previously reported) had interruption distal to the left carotid artery, with the left subclavian artery originating from the descending aorta. ${ }^{12}$ It may be more difficult to distinguish severe preductal coarctation or tubular hypoplasia of the aortic isthmus from aortic arch interruption distal to the left subclavian owing to problems with lateral resolution at the lower limits of the equipment (Fig. 9). The management of these conditions is similar, so exact preoperative differentiation may not be very important.

What then are the pitfalls to be observed when assessing a neonate or infant with suspected coarctation? The first is that in the standard long axis cut of the aorta the coarctation may not be seen at all (Fig. 6). Our experience indicates, however, that the great majority of coarctations will be seen if the transducer is rotated into the ductal cut (Figs. 4-6). If a shelf is still not seen then a careful assessment of the abdominal aorta should be carried out (Fig. 7). The second pitfall is that if there is an isthmic hypoplasia and a wide open ductus, and no coarctation is seen, it is then not possible to rule out a discrete coarctation (Fig. 10). This difficulty would not be resolved if the absolute echocardiographic measurements were closer to the angiocardiographic values as overlap with the values in the normal population is still the problem. Similar difficulties may occur with angiocardiograpy, however, so that it may be necessary to recommend ligation of the ductus with measurement of the pressure difference across the presumptive site immediately after ligation to ensure that no untreated coarctation is left behind. The third pitfall is that the site of entry of a ductus into the front wall of the aorta should not be confused with a coarctation (Fig. 11). If the transducer is angled into the ductal cut it will become clear that the regions above, opposite, and below the ductus are normal (Fig. 12). The fourth pitfall is that pseudocoarctation should not be confused with true coarctation. If the aorta is assessed segmentally, then each segment can be viewed independently of the others (Fig. 13). In this way reliance on one single long axis cut can be avoided.

How then may this assessment of neonates and infants with suspected coarctation affect their future management? It is our policy at this hospital that if a coarctation is suspected clinically and confirmed by cross-sectional echocardiography, provided that the intracardiac anatomy does not itself necessitate a cardiac catheterisation, patients may be submitted for operation without prior invasive investigation. This policy clearly includes patients with no major intracardiac defect or intracardiac defects which would not in any case be repaired at this age, such as mitral stenosis. If aortic stenosis is suspected left ventricular and aortic pressures can be measured at oper- 


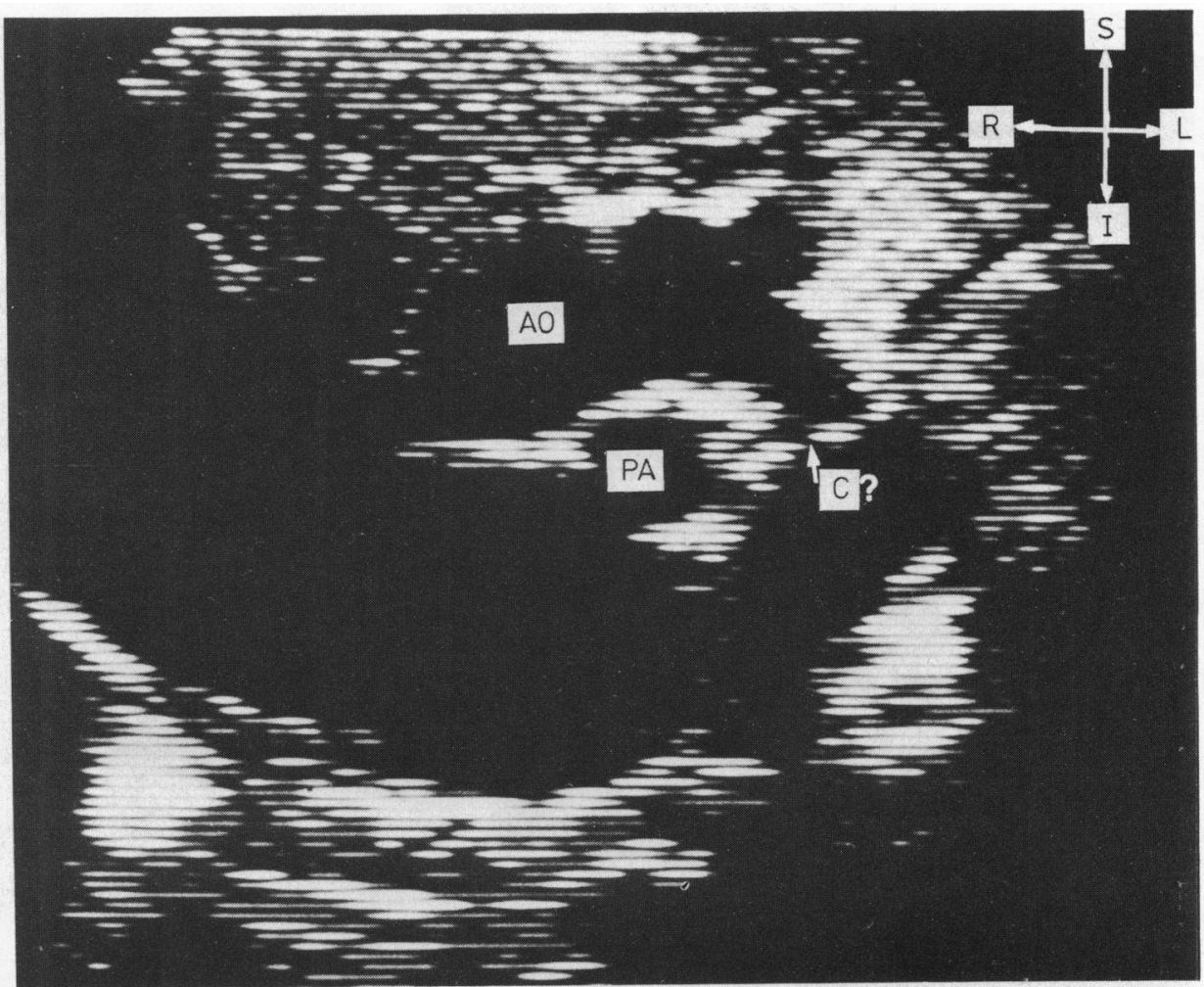

Fig. 11 Cross-sectional echocardiogram of a suprastermal long axis cut in isolated ductus in a neonate. Note the line across the lumen and the dilatation distally which may or may not represent a coarctation. AO, aorta; $P A$, pulmonary artery; $C$, coarctation.

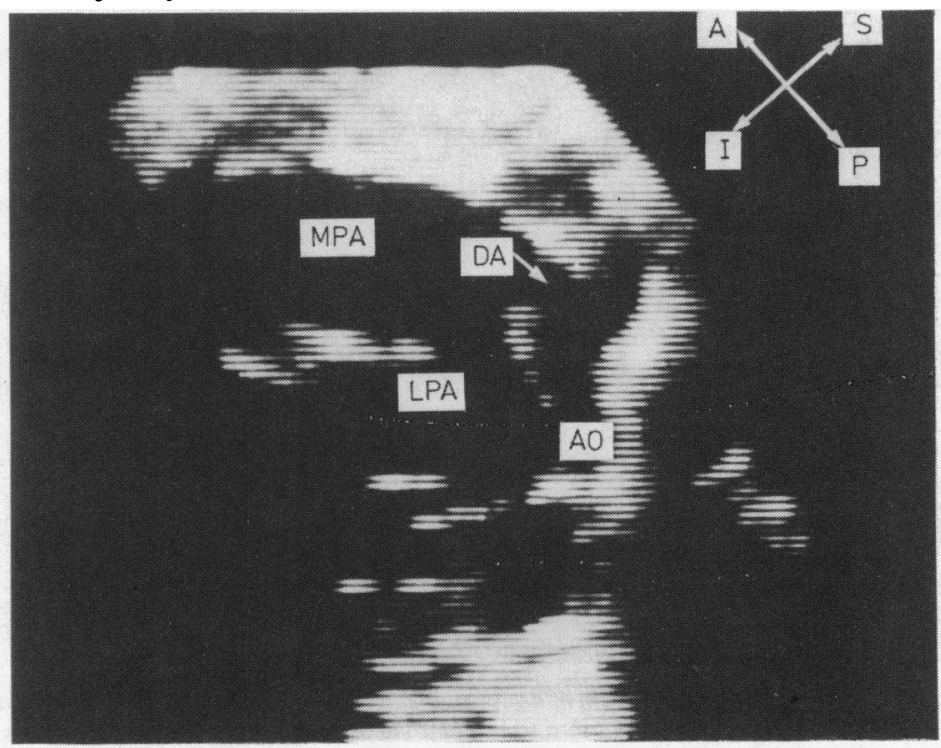

Fig. 12 Cross-sectional echocardiogram of ductal cut in isolated ductus.

Note that the aorta above, opposite, and below the ductus is of normal size. 

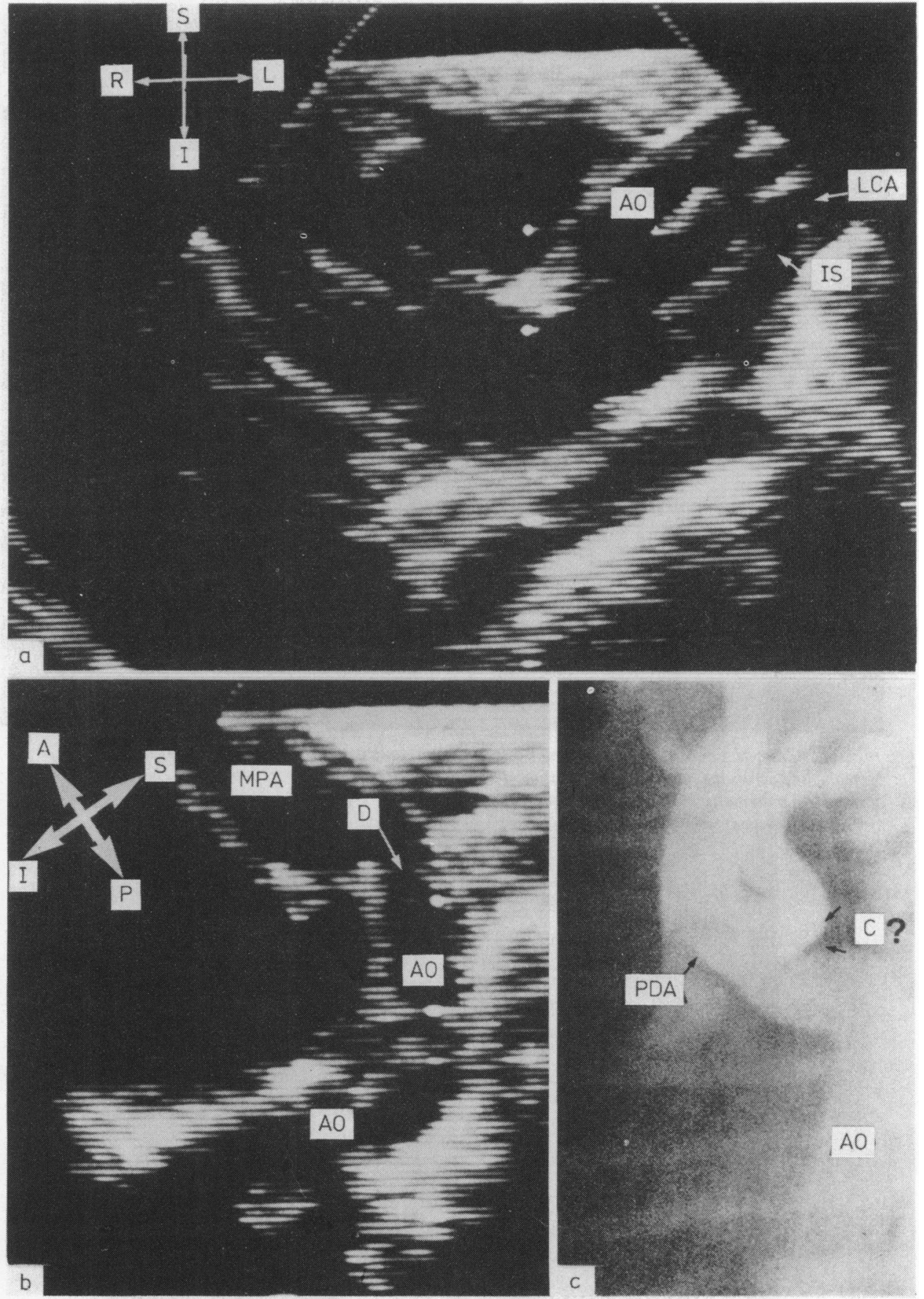

Fig. 13 (a) Cross-sectional echocardiogram of a suprasternal long axis cut in a patient with pseudocoarctation (note that the isthmus appears to be normal in size and that the aorta is kinked); (b) an echocardiogram (from the same patient) showing a large ductus with the distal region being of normal calibre; and (c) an angiocardiogram (from the same patient) showing the kinked aorta and the ductus. PDA, persistent ductus arteriosus; $A O$, aorta; IS, isthmus; LCA, left coromary artery; $C$, coarctation. 
ation and appropriate action taken. In mosi cases nothing will be done at this stage, but should critical aortic stenosis be found we would proceed to a midline sternotomy and aortic valvotomy under inflow occlusion. ${ }^{16}$ In patients with complete transposition with ventricular septal defect, tricuspid atresia, and double outlet right ventricle without pulmonary stenosis, pulmonary artery banding at the time of coarctation repair is in any case the rule in our institution, so that cardiac catheterisation is probably unnecessary. It is only in patients with major ventricular septal defects and normal cardiac connections that our present policy on whether or not to band the pulmonary trunk depends on the findings at cardiac catheterisation. ${ }^{1}$ The assessment of coarctation by clinical examination alone is inadequate as associated intracardiac defects may be missed. Furthermore, interruption of the aortic arch proximal to the left subclavian artery cannot necessarily be ruled out. This carries a higher mortality and requires a different surgical approach. If the suggested flow chart (Fig. 8) is used, it is very unlikely that a false positive diagnosis will be made. Some false negative diagnoses may be inevitable, but these patients would in any case have been catheterised according to conventional practice. Since the beginning of this study 29 neonates and infants have been submitted for surgery without prior cardiac catheterisation. In only two patients studied early in the series was an error made, and in neither was this disastrous. One had an abdominal coarctation (recognised retrospectively) (Fig. 7), and the other palpable femoral pulses with a blood pressure difference of $30 \mathrm{mmHg}$ between the upper and lower limits measured by Doppler technique and an anterior shelf corresponding (as we now realise) to the entry point of the ductus (Figs. 11 and 12). This was patent and in any case required ligation. Neither of these errors would have been made had the proposed flow chart been used.

Thus, provided that potential pitfalls are always borne in mind, a combined clinical and echocardiographic assessment allows most neonates and infants with coarctation of the aorta to be managed surgically without prior invasive studies.

\section{References}

1 Leanage R, Taylor JFN, de Leval MR, Stark J, Macartney FJ. Surgical management of coarctation of the aorta with ventricular septal defect. Multivariate analysis. $\mathrm{Br}$ Heart f 1981; 46: 269-77.

2 Sutherland GR, Godman MJ, Smallhorn JF, Guiterras P, Anderson RH, Hunter S. Ventricular septal defects.
Two dimensional echocardiographic and morphological correlations. Br Heart $\mathcal{F}$ 1982; 47: 316-28.

3 Smallhorn J, Tommasini G, Deanfield J, Douglas J, Gibson D, Macartney F. Congenital mitral stenosis. Anatomical and functional assessment by echocardiography. Br Heart f 1981; 45: 527-34.

4 Smallhorn JF, Huhta JC, Anderson RH, Macartney FJ. Suprasternal cross-sectional echocardiography in assessment of patent ductus arteriosus. Br Heart $\mathcal{F} 1982$; 48: 321-30.

5 Sahn DJ, Allen HD, McDonald G, Goldberg SJ. Realtime cross-sectional echocardiographic diagnosis of coarctation of the aorta. A prospective study of echocardiographic-angiographic correlations. Circulation 1977; 56: 762-9.

6 Marquis RM, Godman MJ. Nomenclature of the ductus arteriosus [Letter]. Br Heart $\mathcal{F}$ 1983; 49: 288.

7 Huhta JC, Smallhorn JF, Macartney FJ. Two dimensional echocardiographic diagnosis of situs. Br Heart $\mathcal{F}$ 1982; 48: 97-108.

8 Smallhorn JF, Anderson RH, Macartney FJ. Two dimensional echocardiographic assessment of communications between ascending aorta and pulmonary trunk or individual pulmonary arteries. $\mathrm{Br}$ Heart $\mathcal{f} 1982$; 47: 563-72.

9 Sinha SN, Kardatzke ML, Cole RB, Muster AJ, Wessel HU, Paul MH. Coarctation of the aorta in infancy. Circulation 1969; 40: 385-98.

10 Keith JD, Rowe RD, Vlad P. Heart disease in infancy and childhood. 3rd ed. New York: Macmillan, 1978: 4-6.

11 Deverall PB, Taylor JFN, Sturrock GS, Aberdeen E. Coarctation-like physiology with cerebral arteriovenous fistula. Pediatrics 1969; 44: 1024-8.

12 Smallhorn JF, Anderson RH, Macartney FJ. Crosssectional echocardiographic recognition of interruption of aortic arch between left carotid and subclavian arteries. Br Heart f 1982; 48: 229-35.

13 Rudolph AM, Heymann MA, Spitznas U. Hemodynamic considerations in the development of narrowing of the aorta. Am $\mathcal{F}$ Cardiol 1972; 30: 514-25.

14 Becker AE, Becker MJ, Edwards JF. Anomalies associated with coarctation of aorta. Particular reference to infancy. Circulation 1970; 41: 1067-75.

15 Ho SY, Anderson RH. Coarctation, tubular hypoplasia, and the ductus arteriosus. Histological study of 35 specimens. Br Heart $\mathcal{F}$ 1979; 41: 268-74.

16 Sink JD, Smallhorn JF, Macartney FJ, Taylor JFN, Stark J, de Leval MR. Management of critical aortic stenosis in infancy. $\mathcal{F}$ Thorac Cardiovascular Surg (in press).

Requests for reprints to Professor F J Macartney, The Hospital for Sick Children, Great Ormond Street, London WCIN 3JH. 